POLIGRAFÍAS. REVISTA DE TEORÍA LITERARIA Y LITERATURA COMPARADA. NÚMERO 1. NUEVA ÉPOCA. OUNAM TODOS LOS DERECHOS RESERVADOS

https://doi.org/10.22201/ffyl.poligrafiasnuevaepoca.2011.1.1648

\title{
Poemas prismáticos: Pessoa e Pessanha
}

HORÁCIO COSTA

Universidade de São Paulo

Na origem, sem dúvida está Cézanne: em suas telas, pouco a pouco o tema deixa de sê-lo, para tornar-se exercício de perscrutação plástica, e mais propriamente pictórica, sobre o mundo e seu ordenamento interno, não-transcendente nem imanente: seu ordenamento em si. Assim, o monte Sainte-Victoire torna-se um sólido subdividido em facetas pigmentadas - prismáticas, sim, prismáticas - que se multiplicam e variam conforme o dia e a tela, conforme a percepção dirigida do pintor que a exercita, eqüidistante de um monte genérico - por exemplo, o Olimpo segundo o Classicismo-, e de uma montanha em seu valor alegórico, como em alguns dos melhores românticos -Caspar David Friedrich, por exemplo-. Por sua vez, os rochedos de Bibémus, que Cézanne pinta ao final de sua vida, parecem incendiar-se por dentro, nas breves pinceladas terracota que os definem: as rochas tornam-se espectrografias consistentes e o pintor parece resgatar, desapaixonadamente é certo, não a "luz simbólica" que assiste às "correspondências", mas a possibilidade da fusão dela e da matéria em sua visão "objetiva", e porque não dizer, lúcida, e por este termo entendamos não-anedotal. Na origem da evolução de toda a arte plástica de há cem, cento e tantos anos, por certo esteve Cézanne, o indomável obsessivo e o silencioso analista que, sem embargo, disse querer "abordar a natureza através do cilindro, da esfera, do cone",1 o ranzinza e o melhor amigo que Renoir teve, e que se considerava o "primitivo" de uma arte nova. ${ }^{2}$ E que disse rotundamente que "a pintura não tem mais objeto do que ela mesma" (Ponente, 1965: 21).

\footnotetext{
${ }^{1}$ Correspondência - Paul Cézanne (1992: 244). Assim corre a passagem, escrita em carta de Cézanne a Émile Bernard (datada de Aix en Provence, 15 de abril de 1904): "Permita-me repetir aqui o que eu lhe dizia: abordar a natureza através do cilindro, da esfera, do cone, colocando o conjunto em perspectiva, de modo a que cada lado de um objeto, de um plano, se dirija a um ponto central. As linhas paralelas ao horizonte dão a extensão, ou seja, uma seção da natureza ou, se preferir, do espetáculo que o Pater Omnipotens Æterne Deus expõe diante dos nossos olhos. As linhas perpendiculares a esse horizonte dão a profundidade" (1992: 244-5).

2 "I shall always remain the Primitive of the path I have opened up" (Delevoy, 1965: 74).
} 
Não é nenhuma novidade isso tudo: os grandes historiadores da arte já lhe estabeleceram este lugar há décadas e reconheceram-lhe a primazia os seus continuadores no período de auge do cubismo, um certo Picasso, um Gris, um Braque, até os seus mais "puros" descendentes: Mondrian, Van Dœsburg, Malévitch e, enfim, Duchamp. Toda uma linhagem analítica, abstrativizante, todo um sentido de espaço brota com Cézanne, e ramifica como os seus pinheiros, um deles, o do Museu de Arte de São Paulo-MASP, uma imagem que viaja em mim desde a infância. Cézanne está para a "imaterialização" do olhar, do olhar que se desprende do tema, do objeto, da anedota, uma vertente perseguida de geração em geração na arte moderna, assim como os mestres do Renascimento estiveram para a descoberta e a afirmação da perspectiva, do olhar centralizado, como o teatro da razão ocidental em termos históricos, filosóficos e plásticos. Na verdade, Cézanne talvez possa entrar para o contexto de formação da sensibilidade da arte moderna não apenas como o inventor desse novo olhar "imaterializador", mas como o pintor que, num movimento de sentido contrário, primeiro procurou materializar, sem lançar mão a legendas ou narrativas de qualquer sorte, o invisível, e particularmente a luz até então funcional para a descrição volumétrica ou simbólica da representação pictórica, tornando-a visível, como problema de base para uma nova visualidade. Aqui, acompanho o pensamento de Merleau-Ponty: “O ser visível é natural, construído em torno da coisa natural. Mas a linguagem, a arte, a história, gravitam em torno do invisível" (Merleau-Ponty, 2000: 365-366); e "o invisível provê o relevo e a profundidade para o visível" (Delevoy, 1965: 74). ${ }^{3}$ Pintar o invisível e escrutar a luz que reside não nas superfícies, mas entre os volumes representados, foi a descoberta máxima de Cézanne; isto equivale, em termos plásticos, à grande inovação einsteiniana, de que o que importava não era o que acontecia dentro mas sim entre os corpos. A revolução da física e a da imagem. O século que passou.

Quando essa sensibilidade deveras nova adentra a escritura da poesia em português? Ela já se viera gestando antes, nem é necessário dizê-lo, e atravessa alguns dos mais importantes poemas do romantismo europeu, de "Tintern Abbey" de Wordsworth (1797) -quando, a uma

\footnotetext{
${ }^{3}$ Assim corre a passagem no ensaio de Delevoy: "If when painting (c. 1895) Millstone at the Château-noir Cézanne appears to waiver between two attitudes, this very hesitation seems to contain the promise of a new dimension, in which (as Merleau-Ponty points out) 'the invisible provides the relief and depth of the visible' (Schelling had voiced the same idea in much the same terms)".
} 
distância panorâmica, o poeta diz que podia ver "into the life of things", numa percepção mais bem física, que não metafísica, da vida- a alguns momentos dos "Canti" de Leopardi-quem diz, em "L'infinito" (1819), ao observar o céu estrelado, que "il naufragar m'è dolce in questo mare", encurtando assim a distância entre sujeito e cosmos-. Dos mais expressivos nomes do Romantismo até a novidade diccional da vanguarda, perfeitamente encapsulada nos versos nervosos, simultaneizadores, poliédricos -numa palavra, cubistas- de "Zone", que Apollinaire escreve em 1912, muito consumiu essa longa gestação, que aponta para o fusionamento, no terreno da produção artística, de uma sensibilidade estética inaugural com uma excitante panóplia de recentes informações científicas, principalmente cosmológicas e físicas, num momento histórico marcado, como dizem os alemães, por um novo Zeitgeist.

Então, quais seriam as marcas da chegada desse sentir ao universo da lírica escrita em português? Tenho algumas hipóteses. Penso, para demarcar um primeiro momento, em Eugênio de Castro e em Teixeira de Pascoais. Neste primeiro momento importaria, para a minha demarcação, a busca de anotação, no corpo do poema, de momentos de difícil apreensão, que assinalariam a busca de plasmação de uma visão nova sobre a natureza e o espaço fusionante, interior/exterior, isto é, subjetivo $e$ objetivo, num instante preciso, que oferece a matéria ao poema. Algo previsivelmente, considerando o vocabulário estético do simbolismo, a matéria do sonho e da visão transmudadora, unidas pelo fio condutor da luz, da exploração consciente, pelos poetas, das diferentes instâncias de significação da graduação da luminosidade, oferecem os topói aos poemas de Eugênio de Castro e Teixeira de Pascoaes que selecionei.

Pensemos primeiramente no poema XI de Oaristos (1 $1^{\underline{a}}$ ed. 1890) -aquele que é construído ao redor da repetição ritmada da estrofe que começa "Na messe, que enlourece, estremesse a quermesse/ o sol, o celestial girassol, esmorece [...]" (Castro, 2001: 94), ${ }^{4}$ e cujos valores fônicos, tão auto-evidentes, como que obnubilaram interpretações do poema deles deliberadamente desvinculadas. No meu ponto de vista, o mais interessante nele não é a sua patente musicalidade, afinal parte da estética simbolista como um todo, mas a "arqueologia do despertar" que processa: pensemos que a estrofe final desfaz o clima de sonho ou de onirismo 
parcialmente voluptoso e parcialmente bizarro, em termos libidinais, se não francamente necrófilos, que dominara todas as estrofes anteriores. Repito-a:

Três da manhã. Desperto incerto... E essa quermesse?

E a Flor que sonho? E o sonho? Ah! Tudo isso esmorece!

No meu quarto uma luz luz com lumes amenos,

Chora o vento lá fora, à flor dos flóreos fenos [...].

Com as três badaladas que dá o sino madrugador, desfaz-se o sonho que cada vez mais levara o eu-lírico, o putativo noivo "a quem fugiu a Flor de olhos amenos/ E chora a sua morta, absorto, à flor dos fenos" (estrofe sétima), a sugar dos seus assustadores "lábios de cinábrio" (estrofe undécima). Toda a carga sexual que o poema acumula evapora-se no contraste entre o crescendo libidinal e a referida estrofe final que, por assim dizer, "desperta-o": nesse momento, o leitor dá-se conta de que o que tentara plasmar o poema é o contraste entre o homem adormecido e o acordado, entre subconsciente e consciente e, consequentemente, entre desejotabu e interdição social. Com isso a sua matéria revela-se como a captação de um despertar difícil, se não de um coitus interruptus; nesse despertar, toda a luz amarelo-dourada que se irisa ao longo do poema tende metaforicamente a reduzir-se à bruxuleante chama da vela (infere-se que de uma solitária vela) que, como vimos, "luz com lumes amenos", e que saúda a visão da realidade, recuperada pelo eu-lírico que se surpreende com a consciência no instante mesmo em que tenta captar os resíduos do sonho que, simultaneamente, desaparece. Poema escrito sobre um limite, na fronteira do desejo com a pulsão, este "oaristo" de Eugênio de Castro, um tanto outré, considerando a época de sua escritura, abre espaço para a fusão interior-exterior mencionada e exemplifica a busca de um olhar-entre.

Por sua vez, num poema de As sombras (1ª ed. 1907), "A sombra do luar", Teixeira de Pascoais discorre sobre os efeitos luminosos, as microscópicas distorções/invenções do luar sobre uma paisagem de montanha, como se procedesse a um levantamento minucioso daquilo que é invisível à solar luz da razão e das aparências que ela propicia. Não surpreendentemente, o invisível transforma-se na matéria mesma do poema, como reza a segunda estrofe:

\footnotetext{
${ }^{4}$ Primeiros dois versos da primeira estrofe do “Oaristo no ${ }^{\mathrm{o} I}$ ” (Castro, 2001: 94-97).
} 
[...] E o luar cresce;

É a branca rosa abrindo... E do Invisível

Nascem a aparições desconhecidas

Que me saem, de súbito, ao caminho

Ou, na distância triste, se desenham [...] (Teixeira de Pascoaes, 1996: 66).

Nesse levantamento, as "mãos da lua pálida" esboçam "num lácteo, aéreo gesto [...] perfis espirituais, vultos de sonho, troncos de névoa e anímicos rochedos" (Teixeira de Pascoaes, 1996: 68); sob tal luz que assinala e desloca a fronteira do visível, o sujeito sente-se ressuscitar: "tu, doce luar das solidões,/ Refizeste meu corpo; [...] e as multidões/ Viventes que murmuram, no meu ser,/ E a treva dispersou -vejo-as, de novo,/ Numa só clara vida, concentradas [...]" (Teixeira de Pascoaes, 1996: 69-70). Este refazer-se do sujeito sob esta luz algo mortiça porém reveladora, leva-o a um aguçamento da sua percepção, que se traduz num visionar da estrutura física das coisas, numa viagem a bem dizer atômica pela matéria:

E as cousas me contemplam, tão serenas,

Impassíveis! E vejo dentro delas,

Tremores, tempestades, sobressaltos,

Fundos abismos, lúcidas estrelas!

Desabamentos fragorosos! [...] (Teixeira de Pascoaes, 1996: 71).

Tal discurso não se distancia de um orfismo que o leva, na andadura do poema, a ouvir a voz de uma pedra genesíaca, que se opõe, com as suas lancinantes invectivas, em termos simbólicos, ao etéreo do luar que o atravessa de ponta a ponta até ser tragado pelo "incêndio trágico da Noite" (Teixeira de Pascoaes, 1996: 73). Passando ao largo de tais marcas de uma inefabilizante retórica epocal, o olhar de Pascoais retrata o que não vê, ou bem aquilo que apenas "contravê", no abrigo da contra-luz do luar.

Operações como as de Eugênio de Castro e de Teixeira de Pascoais apontam para a renovação e a ampliação do espectro da percepção na lírica portuguesa; a partir delas, o poema escrito na segunda década do século passado, acompanhando desenvolvimentos similares em outros contextos europeus, pode, por assim dizer, prismar-se. Em outras palavras, pode passar a sobrepor a noção de construção de um olhar estruturador, a essa nova percepção, como se num movimento de exploração, e de concomitante e progressiva conscientização, da mesma. Para 
avaliar o que de fato aconteceu nesse processo, é melhor de uma feita despir-se das noções assentes, e escolares, que a um movimento da inteligência literário-crítica faz suceder um outro, igualmente designável desde fora: aqui se trata de estudar a estruturação de um olhar inclusivo, em termos epistêmicos, que não delimitado em termos taxonômicos. Anoto quais me parecem ser as marcas dessa, digamos, nova mirada, que se traduz, et pour cause, em um conato de geometrização. A idéia de prisma ocorre especificamente aqui.

Em primeiro lugar, Pessoa. “Chuva Oblíqua” -escrito em junho de 1914 e publicado no segundo número de Orpheu- parece constituir-se num pára-ou semi-“programa” do Interseccionismo, como afirma Georg Rudolf Lind. ${ }^{5}$ É um dos tantos “-ismos" pessoanos, mentalizados pelo poeta ao tempo em que curtia a concepção de seus heterônimos. $\mathrm{O}$ interseccionismo, de curtíssima duração, como é consabido, situa-se, no contexto da obra pessoana, entre o Paulismo, em boa medida inspirado pelo Saudosismo de Teixeira de Pascoais, e o Sensacionismo, que Álvaro de Campos "inventa" para dar vazão aos seus muito whitmanianos poemas, e que, nesta sua evidente origem anglo-saxônica, distancia-se do texto produzido pelas vanguardas dos países ditos "continentais" ( aludo aqui ao sentido que tem esta palavra em língua inglesa, até certo ponto derrisório). Aliás, uma forma de entender a maldisfarçada resistência de Pessoa às vanguardas européias - por exemplo para com o Futurismo, conforme uma carta de 1915 ao Diário de Notícias lisboeta estudada por Lind- (Teixeira de Pascoaes, 1996: 67), e oposta ao fascínio de um Mário de Sá-Carneiro por elas, parece-me ter muito que ver não só com um natural espírito de independência de um inventor de um movimento de vanguarda, mas com a desconfiança não menos "natural" de alguém de formação e informação britânicas em relação às vanguardas "continentais". Uma interpretação nesse sentido poder-se ia ver reforçada, por exemplo, por "Marinetti acadêmico" (poema não datado, segundo a edição de Maria Aliete Galhoz, q.v.), um poema ulterior de Álvaro de Campos, que troça com o velho ex-futurista e então fascista militante, e "a [sua] dinâmica, sempre um bocado italiana, f-f-f-f-f-f-f-f" (Pessoa, 1976: 415).

\footnotetext{
5 “(...) o Intereseccionismo, tal como o Paulismo, [pode] ser interpretado mais facilmente à base dos poemas que lhes servem de modelo. Deve-se, pois, considerar conjuntamente a poesia programática 'Chuva Oblíqua' e as passagens das cartas relacionadas com o Interseccionismo, se quisermos definir tanto quanto possível com exactidão a fase de transição entre o Paulismo e as teorias dos heterónimos" (Lind, 1981: 59).
} 
Seja como for, "Chuva Oblíqua" acompanha de perto o espírito a um só tempo analítico e fusionante que une, como um poderoso denominador comum para lá das idiossincracias regionais européias, os movimentos da vanguarda histórica continentais -o Futurismo de Marinetti, o Dadaísmo de Tzara, o Simultaneísmo de Apollinaire e seus companheiros de L'Esprit Nouveau- e insulares, como o "Blast" de Wyndham Lewis e o Imagismo de Pound. E tal, a começar pelo próprio título do poema, no qual a geometrização da imagem se obvia. "Chuva Oblíqua" tem seis movimentos e narra a fusão de dois planos: o de uma paisagem que pouco a pouco se altera -indicando ora um "exterior" -o quintal que o poeta descortina pela janela, com os seus renques de árvores - e ora um "interior" -o quarto ou a mesa na qual escreve- e uma sucessão de imagens que obliquamente, prismaticamente incidem sobre ela, prismaticamente refratam-se nela e com ela fusionam, a partir de um funcionamento imaginário, e através de uma mecânica associativa na qual adquirem um cinetismo próprio.

Ainda que desde o primeiro verso mantenha-se vinculado a uma poética onirizante ("Atravessa esta paisagem o meu sonho de um porto infinito"), pouco depois -sete versos e duas estrofes depois, mais exatamente- esta idéia é interrompida pela intrusão do, digamos assim, paradigma geométrico:

Liberto em duplo, abandonei-me da paisagem abaixo...

O vulto do cais é a estrada nítida e calma

Que se levanta e se ergue como um muro,

E os navios passam por dentro do tronco das árvores

Com uma horizontalidade vertical,

E deixam cair amarras pelas folhas uma a uma dentro [...] (Teixeira de Pascoaes, 1996: 113).

"Não sei quem me sonho", reza o verso seguinte, inaugurando uma outra estrofe, numa tônica particularmente pessoana, denotadora da "estética do alheamento" tão dorsal em sua poesia. Este ordenamento em si é significativo: a um enunciado que revela um cuidado arquitetônico na construção da indefinição entre os planos real e imaginário, carregada de elementos visuais, um consecutivo altamente condensado, lírico em seu tonus e 
gramaticalmente próprio do português -e intraduzível ao inglês-. ${ }^{6}$ Mais do que estender-me por esse caminho, interessa-me frisar aqui a subdivisão visual, simultaneizadora, do texto, através da imagem paradoxal de "horizontalidade vertical", tão própria, convenhamos, da exploração espacial cubista e que, a bem da verdade, se soluciona dialeticamente em termos geométricos através da diagonalidade -da obliqüidade- própria de um... prisma.

Na criação de espaços imaginários que se sobrepõem ou -melhor dizendo- coexistem com a referência "realista" ao lugar nos quais o poeta diz estar escrevendo o que se lê, o poema vai fabricando uma feira com seus corrosséis, danças sensuais da Andaluzia, uma nave de igreja onde "a missa é um automóvel que passa" -futurismo puro!- (Teixeira de Pascoaes, 1996: 114), e onde, a uma dada altura, surgem do papel as pirâmides do Egito, como a reforçar a prismatização dessa enumeração que se quer novidadeira, "caótica", mas que na verdade aponta para a ampliação da percepção do, chamêmo-lo assim, "momento poético" no qual toda esta sucessão imagética se desdobra.

Das "diagonais difusas", conforme reza o verso antepenúltimo da parte três (Teixeira de Pascoaes, 1996: 115), a “dois grupos que encontram-se e penetram-se/ Até formarem só um que é os dois" (Teixeira de Pascoaes, 1996: 115), na parte cinco, até uma certa batuta -outra diagonal- que um certo maestro sacode no ar no princípio da sexta parte do poema, muito reforça a prismatização imagética como origem da operação poética de Pessoa em "Chuva Oblíqua". O raciocínio poético geometrizador, que viemos acompanhando, ganha um aliado na última parte do poema, onde há uma alternância entre a diagonal e a esfera (de uma bola "que tinha do lado/ O deslizar de um cão verde, e do outro lado/ Um cavalo azul com um jockey amarelo..."), que visualmente se despede nos versos finais:

[...] A bola roda pelo despenhadeiro de meus sonhos interrompidos,

E do alto dum cavalo azul, o maestro, jockey amarelo tornando-se preto,

Agradece, pousando a batuta em cima da fuga de um muro,

E curva-se, sorrindo, com uma bola branca em cima da cabeça,

Bola branca que lhe desaparece pelas costas abaixo... (Teixeira de Pascoaes, 1996: 116-117).

\footnotetext{
${ }^{6}$ Por exemplo: "I do not know who dreams me" não cobre toda a irisação semântica da caprichosa conjugação em português, "I do not know who myself dreams me" soa perfeitamente anômalo, e "I do not know who dreams me in
} 
Se em Pessoa a arquite(x)tura do poema se descobre de forma progressiva ao passo que revela intencionalidade por parte do poeta, a meu ver essencial para a sua compreensão, em Pessanha, cuja capacidade de concisão não deixará de ser admirada pelas gerações futuras, a exploração da imagem através de um raciocínio geometrizador-desconstrutivo, se quisermos-, se dá de chofre, fruto de uma imaginação antes visionária que programática. Uso intencionalmente a palavra "visionária", no duplo sentido, no lato de exercício do sentido da visão, e daí de ampliação do visível, e no translato, a partir deste, de exercício de uma visão futurante, em devir, em levantamento do invisível. Em suma, penso no justificadamente célebre poema "Violoncelo", que aqui recupero:

Chorae, arcadas

Do violoncélo,

Convulsionadas

Pontes aladas

De pesadêlo...

De que esvoaçam

Brancos, os arcos.

Por baixo passam,

Se despedaçam,

No rio os barcos.

Fundas, soluçam

Caudaes de chôro.

Que ruínas, ouçam...

Se se debruçam,

Que sorvedouro!

Lividos astros,

Soidões lacustres...

Lemes e mastros...

E os alabastros

Dos balaustres!

Urnas quebradas.

Blocos de gelo!

Chorae, arcadas

Do violoncélo,

Despedaçadas... (Pessanha, 1994: 130-132).

myself" é, simplesmente, demasiado ampuloso. 
Neste poema, escrito em 1900 porém publicado pela primeira vez em Centauro em 1916, ${ }^{7}$ cujos valores fônicos de fina musicalidade nos absteremos de comentar, observamos com total nitidez a interpenetração, a fusão de duas imagens diferentes: a do violoncelo ele-mesmo, e a de uma paisagem "lacustre", ou ao menos aquática. As "arcadas do violoncelo" já logo na primeira estrofe são assumidas como "pontes aladas de pesadelo". Aqui me interessa sublinhar a correspondência física entre a forma do violoncelo e a das pontes, quando considerados, uma e outras, em vista lateral. Particularmente, chamo atenção para a forma de certas pontes chinesas de três arcos, que têm na parte de sustentação dois arcos menores nas laterais, e um grande, de $180^{\circ}$, de arranque no centro (como, por exemplo, as existentes nos jardins da Cidade Proibida), e um único lance na parte superior e carroçável, e que, portanto, possuem, sempre em vista lateral, uma arcada empinada no centro, sobre o arco central, que cai suavemente em direção a cada uma das laterais, perfazendo um formato pouco usual no Ocidente.

Pessanha, um sinólogo amador (pensemos em sua famosa e discutida coleção de objetos de arte chinesa), que era, recordemo-nos, também um sinófono (considerando as suas traduções do mandarim), parece ter-se dado conta da relação homotética entre as "arcadas" do violoncelo e as das pontes em geral, e particularmente as das pontes chinesas às quais me refiro, e que já tinham fascinado muitos ocidentais -entre outros, Mendes Pinto, o autor da Peregrinação, um dos primeiros europeus a visitar a Cidade Proibida, ainda no séc. XVI-.8 Em poucas palavras, creio que dessa relação homotética, dessa leitura plástica e analógica, espacial, da forma do violoncelo, recebe o poema o seu ponto de arranque, sem desconsiderar, claro está, aquele que é provavelmente o seu maior estopim: o som, a voz do violoncelo propriamente dita. A bem dizer, se se acolher esta leitura, estaremos diante da transformação, da prismatização de um

\footnotetext{
${ }^{7}$ Utilizo a caligrafia original do poema, por sua vez reproduzida na edição crítica de Paulo Franchetti (q.v.) em duas versões (1994: 65-6).

${ }^{8}$ Por exemplo, no cap. XCIX da Peregrinação (Pinto, 1983: 283), lemos: "E hũua das cousas, antes a principal, porque esta Monarchia da China que contem em si trinta \& dous reynos, he tão nobre, tão rica, \& de tão grande trafego, \& comercio, he porque he toda laurada de rios \& esteyros de admirauel feição, muytos q a natureza fez, \& muytos que os Reys, os senhores, \& os poucos antigam ete mandaraõ abrir, para que toda a terra pudesse nauegar \&cõmunicar sem trabalho, dos quais os mais estreitos tem pontes muyto altas, \& compridas \& largas de cantaria muyto forte, feitas ao modo das nossas, \& alg us q hũua só pedra os atrauessa de hũua parte á outra, de oitenta, nouenta \& cem palmos de comprido, \& de quinze\& vinte de largo, cousa certo digna de grandissimo espanto, \& que quasi não se deixa entender como h ua tamanha pedra se possa assi inteyra arrancar da pedreyra, nem mouerse della para se pốr no lugar onde estaua".
} 
objeto em paisagem, os arcos que percorrem as suas cordas feitos velas, "lemes e mastros" de barcos -talvez juncos chineses-, que "por baixo passam,/ Se despedaçam,/ No rio [...]" (quem sabe, ao plangente som do instrumento). Ainda, uma relação homotética pode ser discernida entre os "balaustres" e -sempre em vista lateral, desta feita magnificada-, e os trastos que cortam de espaço a espaço o espelho dos instrumentos de cordas.

Esta leitura pode ser agudizada, se considerarmos que, numa variante autógrafa do poema (1994: 66), Pessanha usa uma palavra -e, claro, uma imagem- do jargão arquitetônico, "plinto" (i.e., base quadrangular de pilares de sustentação de colunas) nos dois primeiros versos da penúltima estrofe -que lê, assim, "Plynthos de rastros/ Fundos lacustres", em vez de "Lividos astros/ Soidões lacustres", o que acrescenta semas para a sustentação da idéia de ponte, expressa acima.

Não prolongo esta leitura. Prefiro terminar este ensaio chamando atenção para a operação de base que parece ter sido a de Pessanha em "Violoncelo": a utilização da chamada por Vico- "lógica poética". Num estudo seminal, "Ideograma, anagrama, diagrama: Uma leitura de Fenollosa",9 Haroldo de Campos aproxima este aspecto preciso ao funcionamento ideogramático. Para o grande sinólogo norte americano, cujos ensinamentos foram trabalhados por Ezra Pound com grande proveito para a poesia moderna, cita Haroldo que "mais do que as coisas, importavam as 'relações' entre [elas]" (Campos, 1986: 43), e que "o que [lhe] interessava era aprofundar essa 'analogia estrutural'"' (Campos, 1986: 45).

Desde a dupla Fenollosa-Pound, habituamo-nos a assumir a convergência entre a escritura oriental e o projeto, presente já no Simbolismo, de fazer coincidir os aspectos verbais, imagéticos e sonoros do poema. Não poderia, nesse sentido, "Violoncelo" ser considerado um exemplo em português desta tendência axiomática da poética moderna, inda mais se considerarmos a já aqui mencionada proclividade de Pessanha pela cultura chinesa? Não valeria aproximar não apenas à poética simbolista manejada em português então (ou mesmo em inglês: como disse, “Violoncelo" foi escrito em 1900, e a leitura de Fenollosa por Pound se dá a partir de 1908), mas também a uma sensibilidade aguçada pela experiência do Oriente, o prisma semântico, em seu aspecto mais fundalmentalmente imagético, que Pessanha constrói no 
poema? Em resumo: e se por detrás do texto de Pessanha estivesse também uma outra idéia de operação poética, não ocidental?

“Divisions prismatiques de l'Idée", escreveu Mallarmé no prefácio a Un coup de dés (1897). O prisma estava no ar, em todos os lugares. Aqui acompanhei a formação desse olhar prismatizante na lírica escrita em Portugal à época. De Cézanne na Provença a Pessanha em Macau, o olhar se aventura e nomeia a estrutura mesma do real como prismática, e pouco a pouco o invisível passa a ocupar a cena do visível no teatro do poema.

${ }^{9}$ Incluído em Ideograma: Lógica Poesia Linguagem (1986). 


\section{Bibliografía}

CAMPOS, Haroldo de (1986): Ideograma: Lógica Poesia Linguagem, São Paulo: Cultrix.

CASTRO, Eugénio de (2001): Obras poéticas de Eugénio de Castro- Tomo I (org. Vera Vouga), Porto: Campo das Letras.

DELEVOY, Robert (1965): Dimensions of the 20th Century - 1900-1945, Genebra: Skira.

LIND, Georg Rudolf (1981): Estudos sobre Fernando Pessoa, Lisboa: Imprensa Nacional/Casa da Moeda. MERLEAU-PONTY (2000): A Natureza, São Paulo: Martins Fontes.

PESSANHA, Camilo (1994): Clepsydra (ed. Paulo Franchetti), Campinas: Editora da UNICAMP.

PESSOA, Fernando (1976): Obra poética (org. Maria Aliete Galhoz), Rio de Janeiro: Editora Nova Aguilar.

PINTO, Fernão Mendes (1983): Peregrinação (trad. Adolfo Casais Monteiro), Lisboa: Imprensa Nacional/Casa da Moeda.

PONENTE, Nello (1965): The Structures of the Modern World -1850-1900, Genebra: Skira.

TEIXEIRA DE PASCOAIS (1996): As sombras/À ventura/Jesus e Pã, Lisboa: Assírio \& Alvim. 